Review

\title{
Studies on Environmental Impact Assessment of Reinforced Concrete in Different Life Cycle Phases
}

\author{
Jair Frederico Santoro and Moacir Kripka \\ Civil and Environmental Engineering Graduate Program, University of Passo Fundo, Passo Fundo, Brazil
}

Article history

Received: 20-11-2017

Revised: $15-12-2017$

Accepted: $27-12-2017$

Corresponding Author:

Moacir Kripka,

Civil and Environmental

Engineering Graduate Program,

University of Passo Fundo,

Passo Fundo, Brazil

Email: mkripka@upf.br

\begin{abstract}
Concrete is one of most used materials in construction and also one of the main responsible for the emission of carbon dioxide, or $\mathrm{CO}_{2}$, in the atmosphere. Thus, in order to study ways to reduce this impact, it is important to evaluate the influence of each raw material of the reinforced concrete, as well as the phases of the life cycle in which these impacts are more relevant. This paper presents a review of recent studies related to carbon dioxide emissions of the materials of reinforced concrete. In this review, we sought to identify the phases of the life cycle of reinforced concrete most focused by researches. It was found that the cement production stage is the most contemplated in the studies, many of them focusing on the additions of complementary cementitious products, since cement is among the materials that contributes decisively to the total $\mathrm{CO}_{2}$ emissions. The structure sizing, with the definition of concrete strength to be adopted in the design, were also extensively investigated, since these are phases in which it is identified a greater possibility of contribution, by the researchers, for the minimization of the impacts.
\end{abstract}

Keywords: Reinforced Concrete, $\mathrm{CO}_{2}$ Emissions, Life Cycle Assessment, Environmental Impact

\section{Introduction}

Concrete is the main building material employed in the world and accounts for a significant share of carbon dioxide or $\mathrm{CO}_{2}$ emissions in the atmosphere (Edvardsen and Tollose, 2001). Although building construction brings undeniable benefits to the community, it is also associated with high costs in terms of environmental impacts. Adopting procedures and strategies to minimize these impacts will require a change in the attitudes and culture of the builders and all others involved in the process (Pullen et al., 2012). One way to minimize environmental impacts is to evaluate each stage of the life cycle of the construction, from the extraction of raw materials to the demolition and waste disposal.

According to Byung et al. (2016), $\mathrm{CO}_{2}$ emission data incorporated in building materials vary significantly, depending on the Life Cycle Assessment (LCA), the country and the time of data formation. In the emission data used in the recent literature, the percentage differences in $\mathrm{CO}_{2}$ emissions on concrete and steel as two typical building materials were up to 267 and $863 \%$, respectively.

Oliveira et al. (2014), in their study of strategies to minimize $\mathrm{CO}_{2}$ emissions from concrete, indicate that many variables that influence the environmental footprint of a concrete can be controlled by those who specify and produce concretes. However, others are controlled by producers of raw materials, especially cement and it is only possible to select the best supplier from among those available. The systematic discussion of the potential of the different strategies to control the concrete $\mathrm{CO}_{2}$ footprint has been absent from the literature.

Still, Hájek et al. (2011) in their study show that the use of optimized concrete structures for the environment creates a potential to increase the quality of the construction and consequently a reduction of the environmental impact. Therefore, any improvement in the principles of concrete mix design, assessment methodologies, construction and demolition technologies and the management of the operation and use of concrete structures is a major contribution to the general objective of sustainable development of society and the environment.

According to Mikulcic et al. (2016), the cement industry worldwide is one of the largest industrial sectors emitting $\mathrm{CO}_{2}$, accounting for a considerable amount of global greenhouse gas emissions. Due to the growing awareness of global warming, the production of more 
energy-efficient cement is being increasingly emphasized, with one of the priorities being to reduce energy demand and to innovate the production process in order to move towards a cleaner production.

Purnell (2012) in his study demonstrated that the structural design parameters (e.g. dimensions and load capacity) for fundamental structural components (beams and columns) are at least as important as the choice of material in relation to its effect on embedded $\mathrm{CO}_{2}$.

Therefore, it can be observed that there are several factors to be studied, evaluated and optimized in the process of minimizing $\mathrm{CO}_{2}$ emissions of reinforced concrete. This article carries out a bibliographical review of recent and relevant studies, trying to verify which of these phases are being most approached and studied and what are the reasons that lead the researchers to this.

\section{Phases of Emissions of Carbon Dioxide of Reinforced Concrete}

To carry out studies related to the environmental impact of reinforced concrete, all involved phases must be considered, starting with the extraction of raw materials. An efficient approach can be performed through the structure life cycle assessment, or LCA.
The cycle evaluation methodology, described by ISO 14040 technical standard, follows four distinct stages: The definition of objective and scope, inventory analysis, impact assessment and interpretation of results. Several environmental indicators can be used during a life cycle analysis study, which are chosen by researchers according to the purpose and scope of the work to be performed.

Life-cycle assessment is a methodology used to evaluate the environmental impact and resources used throughout the life cycle of a product, that is, environmental impact management is approached from the moment the raw material is extracted to the production, use, demolition and recycling phases. In the context of sustainable production in construction, products should be designed so that at the beginning of the life cycle they contain recycled waste as raw material and, at the end of their life cycle, can be recycled and reused to become materials in other production systems. Figure 1 summarizes the life cycle of the concrete adapted from the study of Vieira et al. (2016), with the phases that constitute its productive chain.

A complete example of LCA applied to concrete can be viewed, for example, in Tait and Cheung (2016).

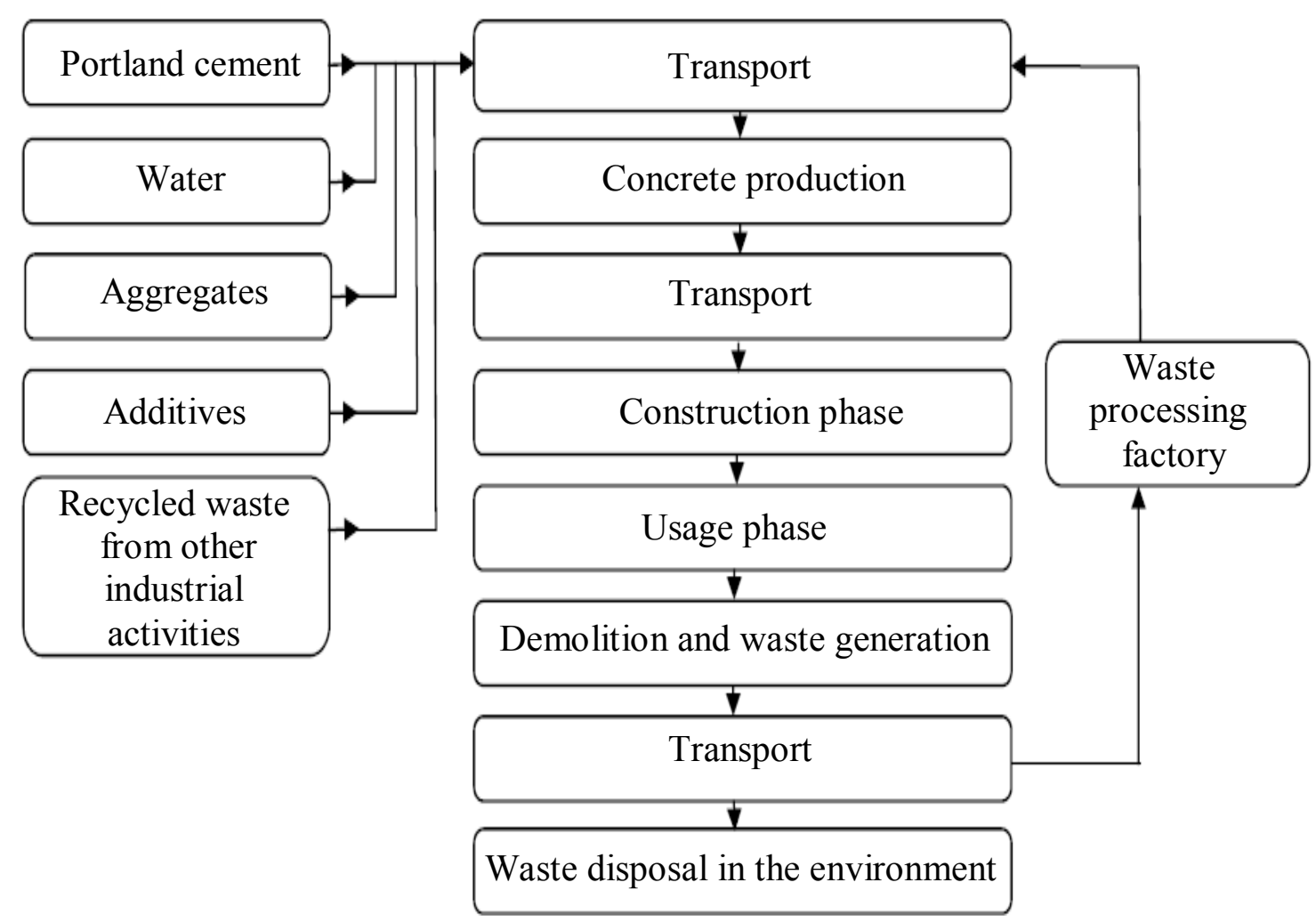

Fig. 1: Life cycle of concrete 


\section{Recent Studies on Emissions of Carbon Dioxide of Reinforced Concrete}

Following are studies on $\mathrm{CO}_{2}$ emissions of reinforced concrete recently carried out in several countries, briefly describing the adopted methodology, the phases studied and the findings and conclusions obtained.

Kim et al. (2016) report that the Korean construction industry accounts for $40 \%$ of total $\mathrm{CO}_{2}$ emissions in the country and that it is essential to reduce these quantities. In their study, they developed an optimization system to minimize $\mathrm{CO}_{2}$ emissions and maximize the economic efficiency of concrete in the cradle-to-gate phase, that is, from the production of the raw material to the point where it leaves the manufacturer's production facilities. The raw materials phase included $\mathrm{CO}_{2}$ emissions during the production of concrete, cement, aggregates and water components, the transportation phase includes $\mathrm{CO}_{2}$ emissions from the transport of raw materials to the concrete plant and the production phase considered the $\mathrm{CO}_{2}$ emissions caused by the generation of electricity and use of fossil fuels in the factory plant. Carrying out a case analysis on a concrete structure design in Korea, using the optimization system, the results obtained indicated that, if the concrete mix and raw material suppliers were selected with the objective of minimizing $\mathrm{CO}_{2}$ emission and the cost of the concrete, one can obtain values with a reduction of $34 \%$ in the emission of $\mathrm{CO}_{2}$ and $1 \%$ in the costs compared to those obtained by conventional methods.

As studies aiming the reduction of carbon dioxide emissions in the building lifecycle becomes increasingly important, it is essential to develop technologies that can quantitatively assess a building's $\mathrm{CO}_{2}$ emissions at the level of building materials. Park et al. (2012) in their study, proposes a method to evaluate the $\mathrm{CO}_{2}$ emissions considering the compressive strength of the concrete and the season of the year. Specifically, the compressive strengths of various concrete mixtures that are adopted in construction sites in Korea were used to evaluate $\mathrm{CO}_{2}$ emissions. Comparisons were also made according to the characteristics of each mixture, concluding that the $\mathrm{CO}_{2}$ emission from the life cycle of the concrete increased linearly to the compressive strength of the concrete, being about $48 \%$ greater to $35 \mathrm{MPa}$ than to $21 \mathrm{MPa}$. With similar compressive strengths, the concrete produced in the winter presented an increase of approximately $5 \%$ in the $\mathrm{CO}_{2}$ emissions when compared to the concrete produced in a standard season. The amount of $\mathrm{CO}_{2}$ emitted by the concrete with additives was $47 \%$ lower (a significant reduction) when compared to the concrete without any addition.
Santoro and Kripka (2016) proposed the determination of $\mathrm{CO}_{2}$ emissions parameters from the production and transportation of raw materials and from the production and transportation of the concrete to the work site, to be used in the design of concrete structures by considering the environmental issue. To evaluate the results obtained, they concluded that producing a concrete with a higher strength will produce a greater amount of $\mathrm{CO}_{2}$ in the environment, mainly because the cement will be present in greater quantity. They emphasize, however, that concrete of greater resistance will be used in smaller volumes. Thus, definitive conclusions can only be obtained after the design of each structure or element, considering also the quantity of steel and its corresponding emissions. In relation to transport, it was found that the $\mathrm{CO}_{2}$ emissions of this stage are significant, due to the long distances covered by two of the four raw materials used in the production of the concrete. The natural aggregate (sand) is the one that has the largest contribution of transport in its total emissions.

In their study, Choi et al. (2016) verified the variability of $\mathrm{CO}_{2}$ emissions in the construction of reinforced concrete structures, seeking to mitigate the environmental impacts of building construction. They developed a model of columns optimization evaluating the influence of the variations in the strength of the materials and its relations with the $\mathrm{CO}_{2}$ emissions. From the optimization of a high-rise building, Choi et al. (2016) concluded that for smaller loads the increase of the transversal area of concrete is more advantageous for the reduction of $\mathrm{CO}_{2}$ emissions and for greater loads the increase of the steel profile produces a more sustainable solution. Regarding the strength of the materials involved, under the effect of high loads, it has been verified that the increase in the strength of steel significantly reduce $\mathrm{CO}_{2}$ emissions and is also more advantageous in relation to the proposed indicator that represents the usability of the projected column space.

Berndt (2015) in his study used the emission values for Australia to compare the influence of the concrete mixtures on wind turbine plant foundations. The study has shown that, when structurally feasible, the use of smaller resistances is advantageous in relation to $\mathrm{CO}_{2}$ emissions, provided that other properties, such as durability, are appropriate to the site conditions and the time life. Also within the same resistance, the use of $65 \%$ of slag rather than $100 \%$ of Portland cement gives a greater reduction in $\mathrm{CO}_{2}$ emissions, from $42.7 \%$ to $32 \mathrm{MPa}$ and $44.8 \%$ to 40 MPa. They conclude that the choice of the concrete mixture strongly influences the magnitude of the $\mathrm{CO}_{2}$ emissions, being able to be optimized to maintain the structural adequacy and to minimize the emissions. 
In addition, Yang et al. (2015) examined the efficacy of complementary cementitious materials such as blast furnace slag, fly ash and active silica in reducing the $\mathrm{CO}_{2}$ emissions of Portland cement used in concrete production by assembling and analyzing a comprehensive database, including 5294 laboratory concrete mixtures and 3915 concrete mixtures under construction. Compressive strength ranges from 8 to $170 \mathrm{MPa}$ and substitution levels of 3 to $80 \%$ blast furnace slag, 3 to $70 \%$ fly ash and 3 to $40 \%$ active silica were considered. The study considered the Korean life cycle from cradle to gate including raw materials, transportation and concrete production phases. They concluded that the intensity of $\mathrm{CO}_{2}$ emissions gradually decreases as Portland cement (up to 15 to $20 \%$ ) is replaced by complementary cementitious materials.

García-Segura et al. (2014) sought to determine if the reduction in emissions of cements mixed with fly ash and blast furnace slag compensates for the reduction of their durability and their carbon capture by carbonation. They evaluated a reinforced concrete column during its life time and after its demolition and reutilization, having gravel as filling material. The results showed that Portland cement concrete, with a mixture of $35 \%$ fly ash and $80 \%$ blast furnace slag, captures 47,41 and $20 \%$ of $\mathrm{CO}_{2}$ emissions, respectively. The life time of the mixed cements, such as $50 \%$ or $80 \%$ blast furnace slag and $35 \%$ fly ash was about $10 \%$ lower. In comparison to Portland cement, despite the reduction in $\mathrm{CO}_{2}$ capture and life time, $80 \%$ blast furnace slag cement emitted $20 \%$ less $\mathrm{CO}_{2}$ per year.

Cabello et al. (2016) evaluated the costs and emissions of greenhouse gases $\left(\mathrm{kg}\right.$ of $\left.\mathrm{CO}_{2}\right)$ generated during the process of constructing a reinforced concrete structure designed for residential use. The type of floor structure selected was flat slabs, which permanently incorporates two materials in the structure: Steel and concrete. Three case studies were used to compare different spacings between the columns, the building having 7 floors and a height of 21 meters and studying the fourth floor. The impact modeling was carried out by SimaPro software in conjunction with the Ecoinvent 2.0 database, incorporating the common characteristics for the construction sector in Spain. As for the impacts generated, in relation to steel, they indicate that slabs with $5 \mathrm{~m}$ of span represent $45.52 \%$ of the emissions, while for slabs with $7 \mathrm{~m}$ of span, steel represents $53.49 \%$. Concrete, on the other hand, undergoes the inverse process, since it represents $52.71 \%$ of impact with $5 \mathrm{~m}$ of span and $45,26 \%$ for $7 \mathrm{~m}$ of span. When evaluating the dimensions of each structure studied and considering the slab with a span of $5 \times 5 \mathrm{~m}$ the optimum value, it is observed that for $\mathrm{CO}_{2}$ emissions there is an increase of $3.78 \%$ for the span of $6 \mathrm{~m}$ and $12.72 \%$ for the span of $7 \mathrm{~m}$. They also conclude that in order to reduce the environmental impact generated by a structure, the focus should be on the first phase of the study, i.e., the production of raw materials, transportation and production of concrete.

Oliveira et al. (2014), in their study in Brazil, report that most concrete emissions originate in the cement production and a traditional strategy of minimizing the $\mathrm{CO}_{2}$ footprint has favored the degree of clinker replacement. They indicated that in relation to the quality control of the productive process of the concrete, there will be a maximum increase of $13 \%$ in the total consumption of cement. They also verified that the variation of cement consumption related to the concrete mixture process demonstrates a great potential for improving the efficiency of the use of the binders. They also concluded that, in general terms, it is not appropriate to base decisions on the emissions of concrete solely on the strength of the concrete and the type of cement used, since the variations are significant.

Paya-Zaforteza et al. (2009) sought to describe a methodology for designing reinforced concrete structures based on the minimization of two objective functions: Embedded $\mathrm{CO}_{2}$ emissions and economic cost. The evaluation followed the Spanish standards and the methodology was applied to six typical structures of up to 8 floors. The results indicate that the two objectives seem to be highly related since the best $\mathrm{CO}_{2}$ emissions solutions are only $2.77 \%$ more expensive than the best cost solutions. Alternatively, the approximate solutions of the best cost worsen $\mathrm{CO}_{2}$ emissions by $3.8 \%$.

Park et al. (2013) carried out a study proposing a sizing method for composite columns of reinforced concrete and steel profiles in tall buildings ( 35 floors), to reduce the cost and $\mathrm{CO}_{2}$ emissions of structural materials during the construction phase. The results obtained from the proposed technique indicated that the weight of the steel section, in the best result, was reduced by $39.14 \%$ while the weight of the concrete was increased by $7.23 \%$. They have argued that reducing the amount of steel and increasing the amount of concrete can be an effective way to reduce the structural costs and $\mathrm{CO}_{2}$ emissions of the columns studied. In obtaining the ideal structure was also considered the use of high strength materials (concrete and steel) in relation to the initial design. They conclude that the use of this type of material for composite elements also reduces $\mathrm{CO}_{2}$ emissions. Thus, even if the 
initial costs and emissions are higher than those of conventional materials, the final results were better because the high-strength materials required smaller volumes for the construction of the columns.

Habert and Roussel (2009) evaluated two different environmental options for sustainable concrete mixtures. The first was the replacement of clinker by mineral additions in cement in order to reduce the environmental cost of the material for a given volume of concrete produced. The second option was to reduce the volume of concrete required for a given construction process, increasing the strength of concrete. They estimated that, in France, $\mathrm{CO}_{2}$ emissions could be reduced by $15 \%$ only by increasing the level of substitution in concrete cement. It was also estimated that the second option could lead to emission reductions of around $30 \%$. Additionally, the authors emphasize that it is also possible to combine cement replacement and increase mechanical strength. From the results and observation of the French practice, this procedure could lead to the reduction of $\mathrm{CO}_{2}$ emissions of up to $40 \%$.

Possan et al. (2016) in their study report that during their life cycle, concrete structures are subjected to carbonation and can absorb part of the $\mathrm{CO}_{2}$ emitted during construction. To evaluate this potential, the study applied mathematical modeling to evaluate the compressive strength performance of a concrete of 20,30 and $40 \mathrm{MPa}$ produced with different types of cements for periods of 0 to 100 years. They indicated that concrete during its life time can absorb from 40 to $90 \%$ of $\mathrm{CO}_{2}$ emitted in the manufacturing process. In some cases, considering the demolition of the structure, its absorption is almost $100 \%$. The percentage of carbon absorption is realized by concrete over its useful life ( 70 years) and during the post-demolition period (up to 30 years). Based on these studies, it was observed that the absorption of $\mathrm{CO}_{2}$ is directly proportional to the surface area of concrete exposed to $\mathrm{CO}_{2}$, influenced by the type of cement and resistance to concrete. The $\mathrm{CO}_{2}$ emissions balance can become an indicator of sustainability and, in the future, can be considered a compensatory measure in the design of concrete structures.

Park et al. (2014) aimed to present design guidelines for reducing $\mathrm{CO}_{2}$ emissions or costs associated with structural materials in the design phase of reinforced concrete columns. Influences of design factors on $\mathrm{CO}_{2}$ emissions or costs were investigated based on the results of a parametric study. They concluded that if the strengths of the structural materials are fixed and the dimensions of the concrete section and the steel area are varied, the steel sections with the lower $\mathrm{CO}_{2}$ emissions are close to the maximum steel ratio, except in cases where that the concrete width increases to satisfy the constraint in the maximum steel ratio. This means that increasing the amount of steel within the allowed range is an efficient approach to reduce $\mathrm{CO}_{2}$ emissions. The steel areas of the lower-cost crosssections are close to the minimum allowed. In addition, it has been found that increasing the strength of the structural materials used is more efficient in reducing both $\mathrm{CO}_{2}$ emissions and costs than increasing the quantities of structural materials used.

Collins (2013) aimed to investigate the ability of recycled concrete to react chemically with $\mathrm{CO}_{2}$ in the air, significantly influencing emission estimates. This work has re-examined $\mathrm{CO}_{2}$ in terms of life cycle definition and proposes encompassing the firstgeneration structure, which covers the time from raw material supply to demolition and includes a second construction incorporating recycled concrete from the original structure. It reports that if carbonation is ignored, emission estimates can be overestimated by up to $45 \%$ depending on the strength of the concrete that was used as well as the type of construction application that incorporates recycled concrete during the second generation. Considering that recycling concrete is a common practice (for example, in Australia it accounts for $74 \%$ of the demolished concrete), the secondgeneration construction following the demolition of the original concrete is to be included in the emissions life cycle estimates of $\mathrm{CO}_{2}$.

Yepes et al. (2012) presented an approach to a methodology for the design of reinforced concrete retaining walls. They used a hybrid multiobjective optimization method, applied to two objective functions: Embodied carbon dioxide $\left(\mathrm{CO}_{2}\right)$ emissions and economic cost of retaining walls of reinforced concrete at different stages of production, transportation and execution. The analysis reveals that $\mathrm{CO}_{2}$ emissions and costs are closely related because the best environmental solutions cost at most only $1.28 \%$ more than the best cost solutions. Alternatively, the best cost solutions increase $\mathrm{CO}_{2}$ emissions by only $1.12 \%$. Thus, acceptable solutions in terms of $\mathrm{CO}_{2}$ emissions are also feasible in terms of cost and vice versa. These results are consistent with previous studies by the research group (PayaZaforteza et al., 2009).

The main results obtained in the above-mentioned studies are summarized in Table 1. 
Table 1: Studies and corresponding main results

\begin{tabular}{|c|c|}
\hline Study & Main results \\
\hline Kim et al. (2016) & $\begin{array}{l}\text { If concrete mix and raw material suppliers were carefully selected, it can be obtained a reduction of } \\
34 \% \text { in the emission of } \mathrm{CO}_{2} \text { and } 1 \% \text { in the costs }\end{array}$ \\
\hline Park et al. (2012) & $\begin{array}{l}\mathrm{CO}_{2} \text { emissions increase linearly with the compressive strength of the concrete; to similar strengths, the } \\
\text { concrete produced in the winter presented an increase of approximately } 5 \% \text { in the } \mathrm{CO}_{2} \text { emissions }\end{array}$ \\
\hline Santoro and Kripka (2016) & $\begin{array}{l}\text { Higher strength concrete will produce a greater amount of } \mathrm{CO}_{2} \text {; the } \mathrm{CO}_{2} \text { emissions during transport are } \\
\text { significant }\end{array}$ \\
\hline Choi et al. (2016) & $\begin{array}{l}\text { For smaller loads the increase of the transversal area of concrete is more advantageous for the eduction of } \\
\mathrm{O}_{2} \text { emissions, and for greater loads the increase of the steel profile produces a more sustainable solution }\end{array}$ \\
\hline Berndt (2015) & $\begin{array}{l}\text { The use of smaller resistances is advantageous in relation to } \mathrm{CO}_{2} \text { emissions; the choice of the concrete } \\
\text { mixture strongly influences the magnitude of the } \mathrm{CO}_{2} \text { emissions }\end{array}$ \\
\hline Yang et al. (2015) & $\begin{array}{l}\text { The intensity of } \mathrm{CO}_{2} \text { emissions gradually decreases as Portland cement is replaced by complementary } \\
\text { cementitious materials (up to } 20 \% \text { ) }\end{array}$ \\
\hline García-Segura et al. (2014) & $\begin{array}{l}\text { In comparison to Portland cement, despite the reduction in } \mathrm{CO}_{2} \text { capture and life time, } 80 \% \text { blast } \\
\text { furnace slag cement emitted } 20 \% \text { less } \mathrm{CO}_{2} \text { per year }\end{array}$ \\
\hline Cabello et al. (2016) & $\begin{array}{l}\text { To reduce the environmental impact generated by a structure, the focus should be on phases of } \\
\text { production of raw materials, transportation and production of concrete }\end{array}$ \\
\hline Oliveira et al. (2014) & $\begin{array}{l}\text { It is not appropriate to base decisions on the emissions of conc } \\
\text { concrete and the type of cement used, since the variations are }\end{array}$ \\
\hline Paya-Z: & Minimization of embedded $\mathrm{CO}_{2}$ emissions and economic cost seem to be highly related \\
\hline Park et & $\begin{array}{l}\text { Reducing the amount of steel and increasing the amount of concrete can be an effective way to reduce } \\
\text { the structural costs and } \mathrm{CO}_{2} \text { emissions of columns }\end{array}$ \\
\hline Haber & It is also possible to combine cement replacement and increase mechanical strength \\
\hline et al. (2016) & $\begin{array}{l}\text { Concrete during its life time can absorb from } 40 \text { to } 90 \% \text { of } \mathrm{CO}_{2} \text { emitted in the manufacturing process; } \\
\text { the absorption of } \mathrm{CO}_{2} \text { is directly proportional to the surface area of concrete exposed to } \mathrm{CO}_{2} \text {, and } \\
\text { influenced by the type of cement and resistance to concrete. }\end{array}$ \\
\hline Park et al. (2014) & $\begin{array}{l}\text { Increasing the strength of the structural materials used is more efficient in reducing } \mathrm{CO}_{2} \text { emissions and } \\
\text { costs than increasing the quantities of structural materials used }\end{array}$ \\
\hline Collins (2013) & $\begin{array}{l}\text { If carbonation is ignored, emission estimates can be overestimated by up to } 45 \% \text { depending on the } \\
\text { strength of the concrete that was used as well as the type of construction application that incorporates } \\
\text { recycled concrete during the second generation }\end{array}$ \\
\hline Yepes et al. (2012) & $\begin{array}{l}\mathrm{CO}_{2} \text { emissions and costs are closely related. Thus, acceptable solutions in terms of } \mathrm{CO}_{2} \text { emissions are } \\
\text { also feasible in terms of cost and vice versa }\end{array}$ \\
\hline
\end{tabular}

\section{Results and Discussion}

In this brief bibliographic review, studies were presented from diverse countries (Fig. 2). In relation to what is being studied, it was verified that the main lines of study are distributed, in the majority, in the production phase of the concrete, taking into account the choice of its strength and the additions in the cement. Approximately $31 \%$ of the studies work with the dimensioning phases of structural elements such as columns, slabs and complete structures and the remaining $19 \%$ in the life cycle more broadly, also considering the carbonation of the concrete during its whole life.

Regarding the phases of the $\mathrm{CO}_{2}$ emissions process of reinforced concrete, the studies evaluated showed that the vast majority works with the cradle to gate phases, involving the production stages of raw materials, transportation, structural design and reinforced concrete.
To facilitate the perception of these behaviors, Fig. 3 shows a flowchart that presents, according to the authors' understanding, the phases that are involved in the $\mathrm{CO}_{2}$ emissions of the reinforced concrete, as well as the indication of the greater or lesser concentration of the studies in each step. Darker tones indicate greater emphasis on the corresponding phase or process.

When analyzing the reasons for the choices of the most studied phases, it can be concluded that one of the main factors is because the stage of cement production and its percentages of additions have a great contribution in the final values of the $\mathrm{CO}_{2}$ emissions of the whole life cycle and that the design of the structure and choice of concrete strength presents greater ease of optimization and control by the researchers. On the other hand, the production and transport phase of the formworks have not received much attention, probably due to the low possibility of interference in the production process and the fact that they do not integrate the structure during its life cycle, unlike concrete and steel. 


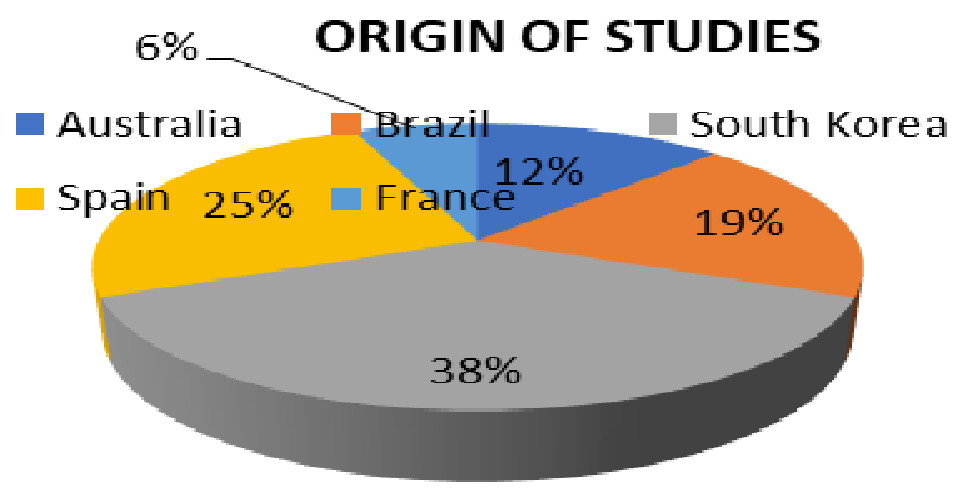

Fig. 2: Countries of studies

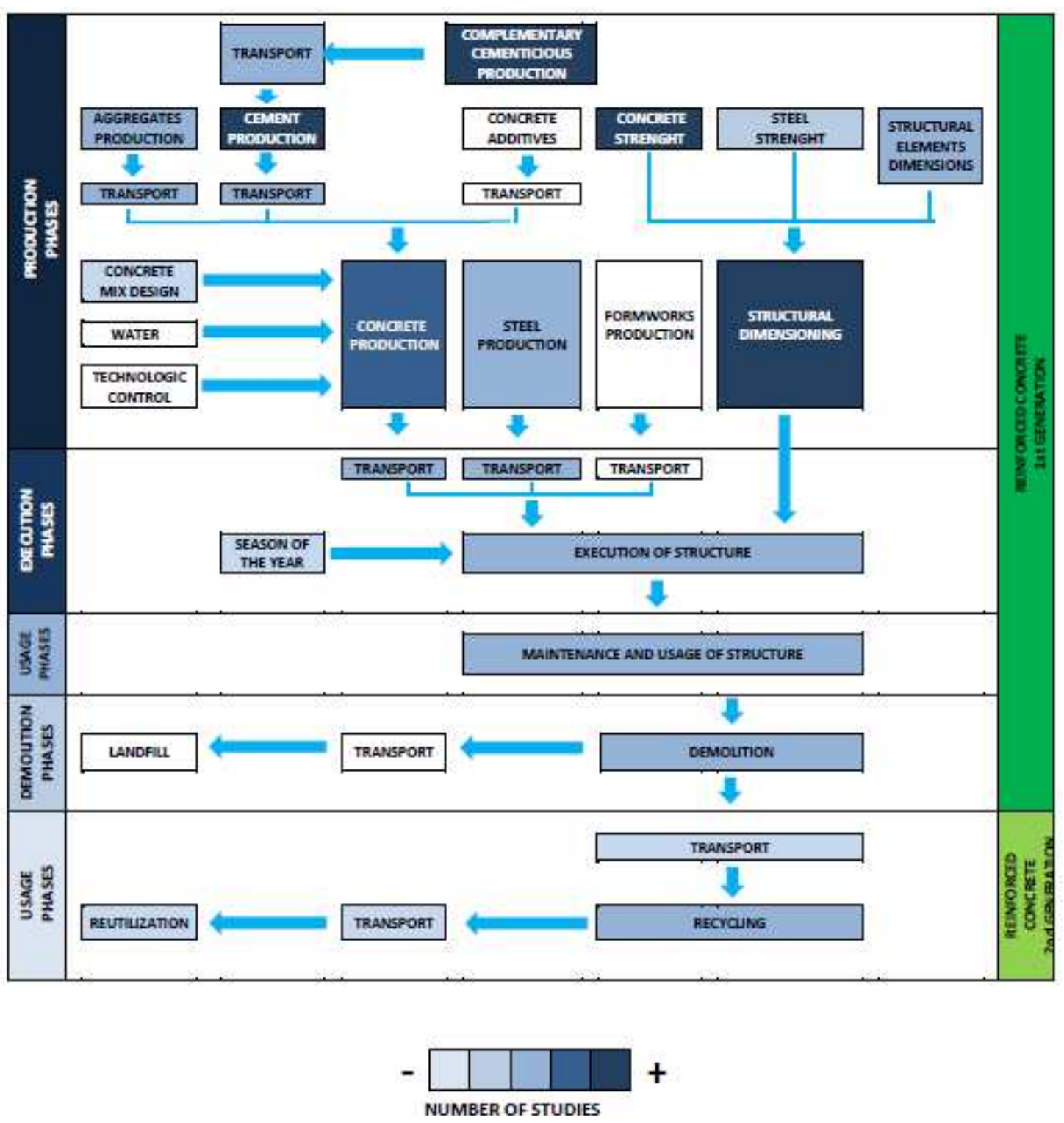

Fig. 3: Emphasis on phases of $\mathrm{CO}_{2}$ emissions of reinforced concrete 


\section{Summary and Conclusion}

In the studies that address the environmental impacts of reinforced concrete (in the present study measured by carbon dioxide emissions), contributions should always be taken into account in the life cycle emissions, from the extraction and production of raw materials, such as cement, aggregates, steel, additives and water, in addition to all transportation issues involved. Also, dimensioning and characteristic strengths of materials should be observed. The production phases of the concrete, with the choice of the most suitable concrete mixture for the defined strength and situations in the use, maintenance and carbonation stages are equally important. Already in the demolition of the structure the final destination of the concrete should be part of the studies, either for landfills or for recycling, in which questions of carbonation may influence again, contributing to minimize the final $\mathrm{CO}_{2}$ emissions of the reinforced concrete.

When the conclusions of the presented studies are observed, the percentages of emission reductions have significant variations due to the specificities of each study, for example, its region of study, the indicators of raw materials used, the methodology of analysis, the structural element considered and the distances covered in the process, among other factors. Thus, a long road must still be traveled so that the impacts can be fully evaluated and effectively reduced.

Although the present study is limited only to carbon dioxide emissions, it is believed that the general observations made here can be extended to other equally relevant forms of measurement, such as energy consumption or global warming potential.

\section{Acknowledgement}

The second author thanks to $\mathrm{CNPq}$ (Brazilian Council for Scientific and Technological Development) for the financial support granted.

\section{Author's Contributions}

Jair Frederico Santoro: Developed the bibliographical review and structured the text.

Moacir Kripka: Contributed to the discussions and to the paper writing.

\section{Ethics}

The Authors declare there's no conflict of interest.

\section{References}

Berndt, M.L., 2015. Influence of concrete mix design on $\mathrm{CO}_{2}$ emissions for large wind turbine foundations. Renewable Energy, 83: 608-614.
Byung, O.K., S.W. Choi and H.S. Park, 2016. Influence of variations in $\mathrm{CO}_{2}$ emission data upon environmental impact of building construction. J. Cleaner Product., 140: 1194-1203. DOI: 10.1016/j.jclepro.2016.10.041

Cabello, J.F., E.F. Garcia, E.M.P. Ascacibar and F.J.M.P. Ascacibar, 2016. Minimizing greenhouse gas emissions and cost for structures with flat slabs. J. Cleaner Production, 137: 922-930.

Choi, S.W., B.K. Oh, J.S. Park and H.S. Park, 2016. Sustainable design model to reduce environmental impact of building construction with composite structures. J. Cleaner Production, 137: 823-832.

Collins, F., 2013. 2nd generation concrete construction: Carbono footprint accounting. Eng. Construction Architectural Management, 20: 330-344.

Edvardsen, C. and K. Tollose, 2001. Environmentally "green" concrete structures. Proceedings of the Fib Symposium Concrete and Environment, (SCE' 01), Berlin, pp: 1-9.

García-Segura, T., V. Yepes and J. Alcalá, 2014. Life cycle greenhouse gas emissions of blended cement concrete including carbonation and durability. Int. J. Life Cycle Assessment, 10: 3-12.

Habert, G. and N. Roussel, 2009. Study of two concrete mix-design strategies to reach carbono mitigation objectives. Cement Concrete Composites, 31: 397-402.

Hájek, P., C. Fiala and M. Kynclová, 2011. Life cycle assessments of concrete structures - a step towards environmental savings. Structural Concrete, 12: 1-1. DOI: 10.1002/suco.201000026

Kim, T.H., S.H. Tae, S.J. Suk, G. Ford and K.H. Yang, 2016. An optimization system for concrete life cycle cost and related $\mathrm{CO}_{2}$ emissions. Sustainability J., 8: $1-16$.

Mikulcic, H., J.J. Klemes, M. Vujanovic, K. Urbaniec and N. Duic, 2016. Reducing greenhouse gases emissions by fostering the deployment of alternative raw materials and energy sources in the cleaner cement manufacturing process. J. Cleaner Product., 136: 119-132.

Oliveira, V.C.H.C., B.L. Damineli, V. Agopyan and V.M. John, 2014. Estratégias para a minimização da emissão de $\mathrm{CO}_{2}$ de concretos. Ambiente Construído, 14: 167-181.

Park, H.S., B. Kwon, Y. Shin, Y. Kim and T. Hong et al., 2013. Cost and $\mathrm{CO}_{2}$ emission optimization of steel reinforced concrete columns in high-rise buildings. J. Energies, 6: 5609-5624.

Park, H.S., H. Lee, Y. Kim, T. Hong and S.W. Choi, 2014. Evaluation of the influence of design factors on the $\mathrm{CO}_{2}$ emissions and costs of reinforced concrete columns. Energy Buildings, 82: 378-384.

Park, J., S. Tae and T. Kim, 2012. Life cycle assessment of concrete by compressive strength on construction site in Korea. Renewable Sustainable Energy Rev., 16: 2940-2946. 
Paya-Zaforteza, I., V. Yepes, A. Hospiraler and F. González-Vidosa, 2009. $\mathrm{CO}_{2}$-optimization of reinforced concrete frames by simulated annealing. Eng. Structures, 31: 1501-1508.

Possan, E., E.F. Felix and W.A. Thomaz, 2016. $\mathrm{CO}_{2}$ uptake by carbonation of concrete during life cycle of building structures. J. Build Rehabil., 1:7: 1-9.

Pullen, S., K. Chiveralls, G. Zillante, J. Palmer and W. Wilson et al., 2012. Minimising the impact of resource consumption in the design and construction of buildings. Proceedings of the Annual Conference of the Architectural Science Association, (ASA’12), Queensland.

Purnell, P., 2012. Material nature versus structural nurture: The embodied carbon of fundamental structural elements. Environ. Sci. Technol., 46: 454-461.

Santoro, J.F. and M. Kripka, 2016. Determinação das emissões de dióxido de carbono das matérias primas do concreto armado produzido na região norte do Rio Grande do Sul. Ambiente Construído, 16: 35-49.
Tait, M.W. and W.M. Cheung, 2016. A comparative cradle-to-gate life cycle assessment of three concrete mix designs. Int. J. Life Cycle Assess., 21: 847-860.

Vieira, D.R., J.L. Calmon and F.Z. Coelho, 2016. Life Cycle Assessment (LCA) applied to the manufacturing of common and ecological concrete: A review. Construction Build. Mater., 124: 656-666.

Yang, K.H., Y.B. Jung, M.S. Cho and S.H. Tae, 2015. Effect of supplementary cementitious materials on reduction of $\mathrm{CO}_{2}$ emissions from concrete. J. Cleaner Production, 103: 74-783.

Yepes, V., F. Gonzalez-Vidosa, J. Alcala and P. Vilalba, 2012. $\mathrm{CO}_{2}$-optimization design of reinforced concrete retaining walls based on a VNS-threshold acceptance strategy. J. Comput. Civil Eng., 26: 378-386. 